person from abuse it is worth it'.

I work in a catchment area for deprived families and patients say, 'You've got to sort out this pain; I can't sleep or eat and I am taking it out on my partner/ kids'. Evidence shows that the majority of abuse is carried out by family members. Preventing abuse by removing people from severe pain is the sort of real world evidence-based outcome our practice aims for and wants to spend money on.

In a system which has no additional funding for regulation, the cost of CRB checks is taken directly from patient care. If you are considering outcomes, surely the idealistic view of preventing one person from possibly reoffending at a cost of $£ 3.6$ million should be balanced against the benefit of treating 48,000 patients (cost £75/patient $\mathrm{x} 48,000=$ $£ 3.6$ million) for dental pain. This has a much better evidence base for reducing abuse within the family and there are considerable spin offs such as fewer hospital admissions for acute care as well!

CRBs are just one small example of this lack of outcome-based thinking; space here limits us from looking at the others. I don't see much evidence for CQC analysing either their original justification or their own outcomes; just reducing dental care by diverting treatment funding. Is this really a good use and how much should we pay them?

S. Baker

Dewsbury

DOI: 10.1038/sj.bdj.2012.1047

\section{SECONDARY CARE BURDEN}

Sir, we are writing with concern regarding the continued increase in the number of odontogenic abscesses presenting to secondary care.

Local and national audits have shown a marked increase in patients presenting to secondary care with odontogenic infection since 1999. ${ }^{1,2}$

Patient admissions for odontogenic abscesses at Leeds General Infirmary have continued to increase in number since 2006; the number of admissions has increased four fold from 48 in 2006 to 198 in 2011 (Fig. 1).

The distribution of those presenting with odontogenic abscesses pre and post the introduction of the 2006 NHS dental contract is statistically significant,

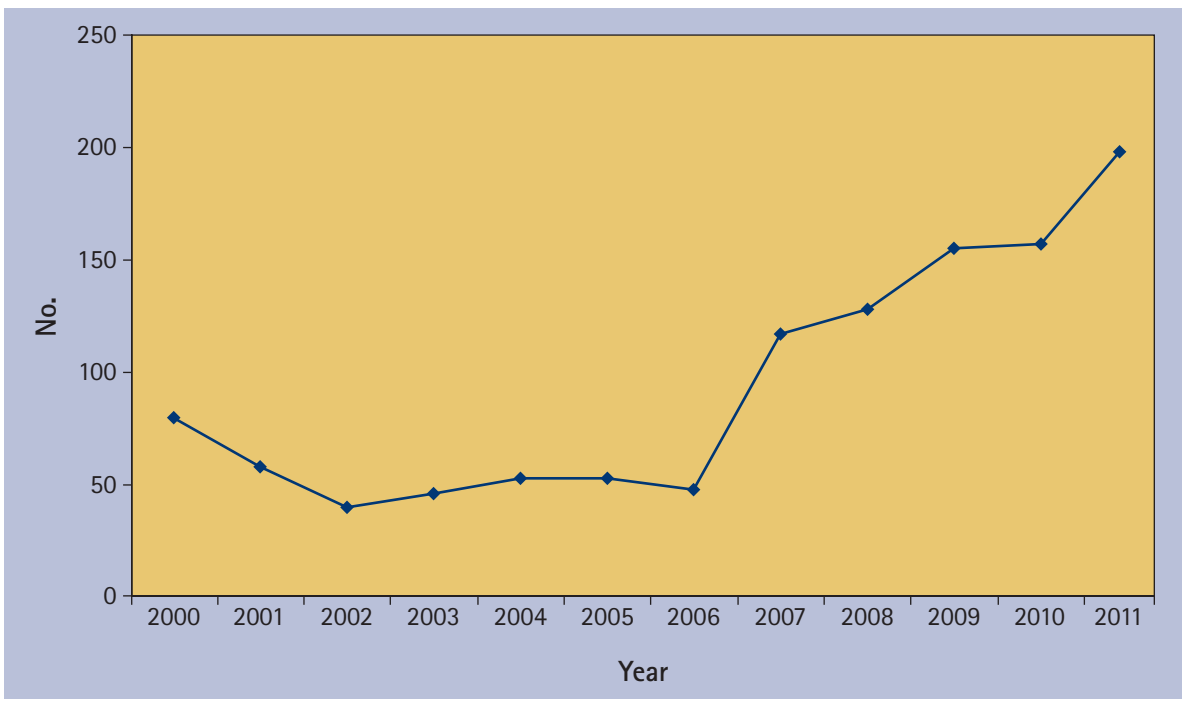

Fig. 1 Odontogenic abscess admissions over time

$\chi^{2}=85.86, \mathrm{df}=5, \mathrm{p}<0.0001$, with this trend continuing to rise.

This rise will only result in more pressure on the already stretched secondary care system, with an increasing workload for Accident and Emergency departments and on emergency theatre facilities.

Explanations for the continuing increase in admissions are varied and complex. Further work is clearly required to identify the main reasons but difficulty of access to NHS or emergency dental care is still widely described. Reduction in initial operative intervention for dental abscesses in primary dental care is also implicated. These issues are potentially due to changes in remuneration upon introduction of the new contract in 2006 causing a reduction in the amount of NHS treatment carried out by GDPs. ${ }^{3}$

In this time of austerity and reduction in hospital bed numbers, the avoidable increase in admissions for odontogenic abscesses is causing an ever-increasing demand on already limited resources. This trend shows the importance of enhanced communication between the primary and secondary care settings, and an increase in emergency funding for our GDP colleagues to reduce the burden on secondary care.

S. King, A. Kanatas, L. M. Carter Leeds

1. Carter $L$, Starr D. Alarming increase in dental sepsis. Br Dent J 2006; 200: 243.

2. Thomas S J, Atkinson C, Revington P. Is there an epidemic of admissions for surgical treatment of dental abscesses in the UK? BMJ 2008; 336: 1219-1220.

3. Carter L M, Layton S. Cervicofacial infection of dental origin presenting to maxillofacial surgery units in the United Kingdom: a national audit. $\mathrm{Br}$ Dent J 2009; 206: 73-78.

DOI: 10.1038/sj.bdj.2012.1048

\section{CATASTROPHIC INJURIES}

Sir, the publication Oral Health Report which arrived with our $B D J$ today, although of useful content, was disappointing in its choice of an inappropriate cover photograph used to illustrate a 'typical' dental team. The picture shows a dentist and close support nurse with turbine in full flow, working on a highly vulnerable, supine patient, but without protective eyewear being worn.

Every training programme for dentists, therapists, hygienists and nurses instils the essential and mandatory nature of eye protection. As educators frequently teaching the whole dental team at all levels, of this we are sure. Catastrophic injuries may easily occur to the patient and/or dentist and nurse, and do, resulting in irreversible ocular damage.

Perhaps the journal should be a tad more careful to cast an eye (pun intended) over such literature distributed within its umbrella.

K. Marshall, K. Marshall By email DOI: $10.1038 / s j . b d j .2012 .1049$

The $B D J$ website now includes a facility enabling readers to immediately comment on letters. All comments must comply with the nature.com Terms and Conditions and Community Guidelines visit the $B D J$ website to find out more and to post your comment now. 